\title{
Human erythrocyte sorbitol metabolism and the role of sorbitol dehydrogenase
}

\author{
Y. Nagasaka, S. Fujii and T.Kaneko \\ The Third Department of Internal Medicine, Yamaguchi University, School of Medicine, Ube, Yamaguchi, Japan
}

\begin{abstract}
Summary. Rapid fluctuation of erythrocyte sorbitol in response to the changes in plasma glucose concentration has been reported from clinical evidence. We performed more extensive in vitro and in vivo studies focussing on how fast sorbitol was accumulated and how fast the accumulated sorbitol was oxidised in response to the changes in ambient glucose concentration. Incubation studies of intact erythrocytes from healthy subjects and diabetic patients showed that erythrocyte sorbitol increased rapidly in response to increased ambient glucose concentration and the accumulated sorbitol easily decreased according to the rapid reduction of ambient glucose concentration. In addition, the higher the glucose concentration in the medium, the more erythrocytes could accumulate sorbitol. The rapid response of sorbitol
\end{abstract}

levels to ambient glucose concentration was further confirmed by the results of a $75 \mathrm{~g}$ oral glucose tolerance test in non-diabetic subjects and diabetic patients with gastrectomy, who showed marked early hyperglycaemia caused by rapid absorption of ingested glucose and subsequent rapid reduction of plasma glucose concentration (erythrocyte sorbitol levels changed concomitantly). These findings strongly indicate that the measurement of erythrocyte sorbitol is not useful as an index of medium or long term glycaemic control.

Key words: Human erythrocyte, aldose reductase, sorbitol, sorbitol dehydrogenase, polyol pathway.
Some earlier studies have shown good correlation between erythrocyte sorbitol concentration and $\mathrm{HbA}_{1}$ [1-3], and the usefulness of measuring erythrocyte sorbitol as an index of medium or long term diabetic control $[1,3]$. On the other hand, recent clinical studies have shown rapid fluctuation of erythrocyte sorbitol in response to rapid changes in plasma glucose concentration [4-6] and no consistent relationships between erythrocyte sorbitol levels and $\mathrm{HbA}_{1}$ [6]. Therefore, measurement of erythrocyte sorbitol was suggested not to be a reliable indicator of diabetic control. However, only a couple of in vitro incubation studies using intact erythrocytes and high glucose concentrations have been presented, and the precise relationship between ambient glucose concentration and erythrocyte sorbitol levels has not yet been determined.

Human erythrocytes are highly permeable to glucose and this glucose transport is insulin-independent. Human erythrocyte hexokinase has a very low $\mathrm{Km}$ for glucose $(0.05-0.08 \mathrm{mmol} / 1)$ and is saturated even at normal plasma glucose levels $(5 \mathrm{mmol} / \mathrm{l})$ [7], while the $\mathrm{Km}$ of erythrocyte aldose reductase is $9 \mathrm{mmol} / \mathrm{l}$ [8]. Therefore, it seems very reasonable that glucose utili- sation via the polyol pathway does increase during hyperglycaemia, while glucose utilisation via the glycolytic pathway increases only by a very small percentage [7]. Since the erythrocyte membrane is not permeable to sorbitol, the intracellular sorbitol level simply reflects an equilibrium between its formation by aldose reductase and its depletion by sorbitol dehydrogenase [9].

We performed in vitro and in vivo studies focussing on how fast sorbitol was accumulated and how fast the accumulated sorbitol was oxidised in response to the changes in ambient glucose concentration in order to resolve the clinical question whether measurement of erythrocyte sorbitol could serve as a reliable index of diabetic control.

\section{Subjects and methods}

Incubation studies were performed using erythrocytes from five healthy subjects (23-30 years) and four diabetic patients (42-64 years, $\mathrm{HbA}_{1}$ 9.7-12.1\%). Two non-diabetic (60 and 54 years) and two diabetic (69 and 58 years, $\mathrm{HbA}_{1} 9.2$ and $9.8 \%$ ) subjects with gastrectomy underwent a $75 \mathrm{~g}$ oral glucose tolerance test. 


\section{Erythrocyte incubation studies}

Heparinised blood was obtained from healthy subjects and diabetic patients [10], and $500 \mu \mathrm{l}$ of washed erythrocytes were incubated with $2 \mathrm{ml}$ of $0.1 \mathrm{~mol} / \mathrm{l}$ HEPES buffer (pH 7.4), containing $135 \mathrm{mmol} / \mathrm{l}$ $\mathrm{NaCl}$ and $5 \mathrm{mmol} / 1$ glucose, for $1 \mathrm{~h}$ at $37^{\circ} \mathrm{C}$ in a shaking bath for equilibration. Then, glucose was added to the incubation medium to give final concentrations of $5-50 \mathrm{mmol} / 1$ and the incubations were continued for $5 \mathrm{~h}$ at $37^{\circ} \mathrm{C}$. In some experiments, erythrocytes were incubated with $30 \mathrm{mmol} / 1$ glucose for $1 \mathrm{~h}$ and then with $5 \mathrm{mmol} / 1$ glucose. The changes of $\mathrm{pH}$ even after the $5 \mathrm{~h}$ incubations were very small (within 0.05 ) without any difference between 5 and $50 \mathrm{mmol} / 1$ glucose medium.

\section{Oral glucose tolerance test}

In two non-diabetic subjects and two diabetic patients with gastrectomy, the concentrations of plasma glucose and erythrocyte sorbitol were measured during a $75 \mathrm{~g}$ oral glucose tolerance test.

\section{Biochemical procedures}

Sorbitol was measured spectrophotometrically with sorbitol dehydrogenase (from sheep liver, purchased from Sigma, St. Louis, Mo, USA) by a modified method of Beutler [11]. Deproteinised and neutralised samples were added to the reaction mixture containing $2 \mathrm{mmol} / 1 \mathrm{NAD}^{+}$and 1 unit of sorbitol dehydrogenase. Although sorbitol dehydrogenase is not specific for sorbitol, validity of this assay has been proven $[1,12]$. 14]

Glucose and fructose were assayed as reported elsewhere [13,

\section{Sorbitol dehydrogenase assay}

The assay was performed by the method of Barreto et al. [15]. The effects of glycolytic intermediates, nucleotides and fructose on sorbitol dehydrogenase activity were investigated at 2 - and 10 -fold physiological concentrations.

\section{Partial purification of sorbitol dehydrogenase}

Erythrocytes free from leukocytes and platelets were haemolysed, and then passed through a DEAE cellulose column, pre-equilibrated with buffer $\mathrm{A}(10 \mathrm{mmol} / 1$ potassium phosphate, $\mathrm{pH}$ 7.4). The column was washed with buffer A eluting against a linear gradient of $0-0.35 \mathrm{~mol} / 1 \mathrm{KCl}$ in buffer $\mathrm{A}$. The active fractions were pooled and precipitated by ammonium sulfate of $45-60 \%$ saturation. After centrifugation, the pellet was extensively dialysed against buffer $\mathrm{A}$ and used for the sorbitol dehydrogenase assay. Using this approach, lactate dehydrogenase activity was separated from sorbitol dehydrogenase activity. Very low activities of glucose-6-phosphate dehydrogenase remained, but were not detected in the presence of $\mathrm{NAD}^{+}$.

\section{Statistical analysis}

Data are given as means \pm SD. The results were evaluated statistically using unpaired Student's $t$-test.

\section{Results}

Figure 1 shows the time-dependent formation of erythrocyte sorbitol at various concentrations of glucose, using intact erythrocytes from three healthy subjects and four diabetic patients. Although the erythrocyte sorbitol concentration increased in response to increased medium glucose concentration, this sorbitol accumulation was not proportional to the ambient glucose concentration. The higher the glucose concentration in the medium, the more erythrocytes could accumulate sorbitol.

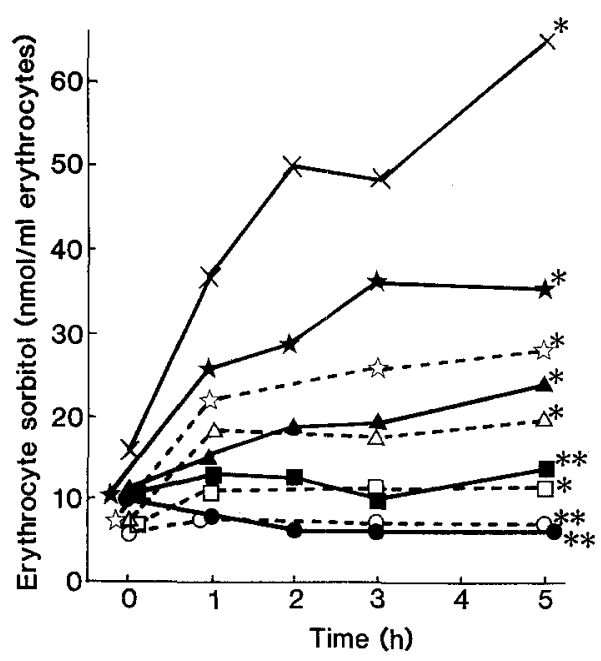

Fig.1. The time-dependent formation of erythrocyte sorbitol. Erythrocytes from three healthy subjects were incubated with glu$\operatorname{cose}(\bullet, 5 \mathrm{mmol} / 1 ; \mathbf{\square} \longrightarrow, 10 \mathrm{mmol} / \mathrm{l}: \longleftrightarrow, 20 \mathrm{mmol} / \mathrm{l}$; $\star \quad \star \quad, 30 \mathrm{mmol} / \mathrm{l} ; \times-\times, 50 \mathrm{mmol} / \mathrm{l})$ for $5 \mathrm{~h}$. Erythrocytes from four diabetic patients, whose $\mathrm{HbA}_{1}$ were $11.3 \pm 0.9 \%$, were incubated with glucose $(\mathrm{O}--\mathrm{O}, 5 \mathrm{mmol} / \mathrm{l} ; \square-\cdots, 10 \mathrm{mmol} / 1 ; \Delta \cdots \Delta$, $20 \mathrm{mmol} / \mathrm{l}$; 4 -.-.s $30 \mathrm{mmol} / \mathrm{l}$ ) for $5 \mathrm{~h}$. The values represent means of three or four duplicate experiments. $\left(^{*}, p<0.05, * *\right.$, NS vs 0 time)

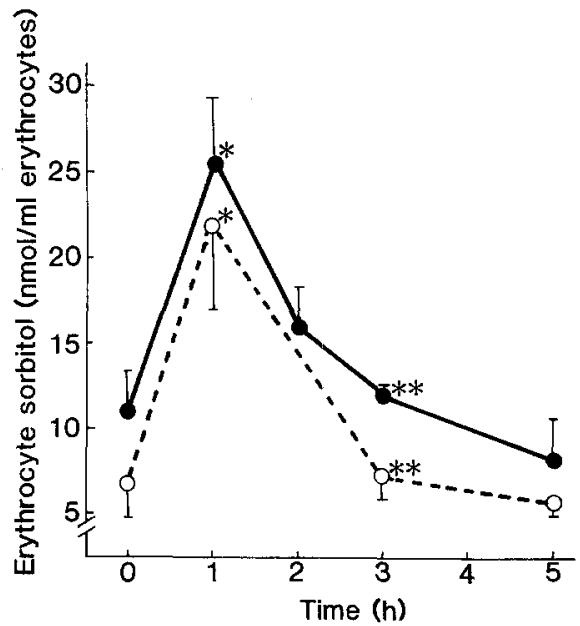

Fig. 2. The rate of oxidation of the increased sorbitol at $5 \mathrm{mmol} / \mathrm{l}$ glucose. Erythrocytes from 5 healthy $(-)$ ) and 4 diabetic subjects $(\mathrm{O}---\mathrm{O})$ were incubated with $30 \mathrm{mmol} / 1$ glucose for $1 \mathrm{~h}$ and then for further $4 \mathrm{~h}$ with $5 \mathrm{mmol} / 1$ glucose. The values represent means $\pm \mathrm{SD} .(*, p<0.05 ; * *$, NS vs 0 time) 


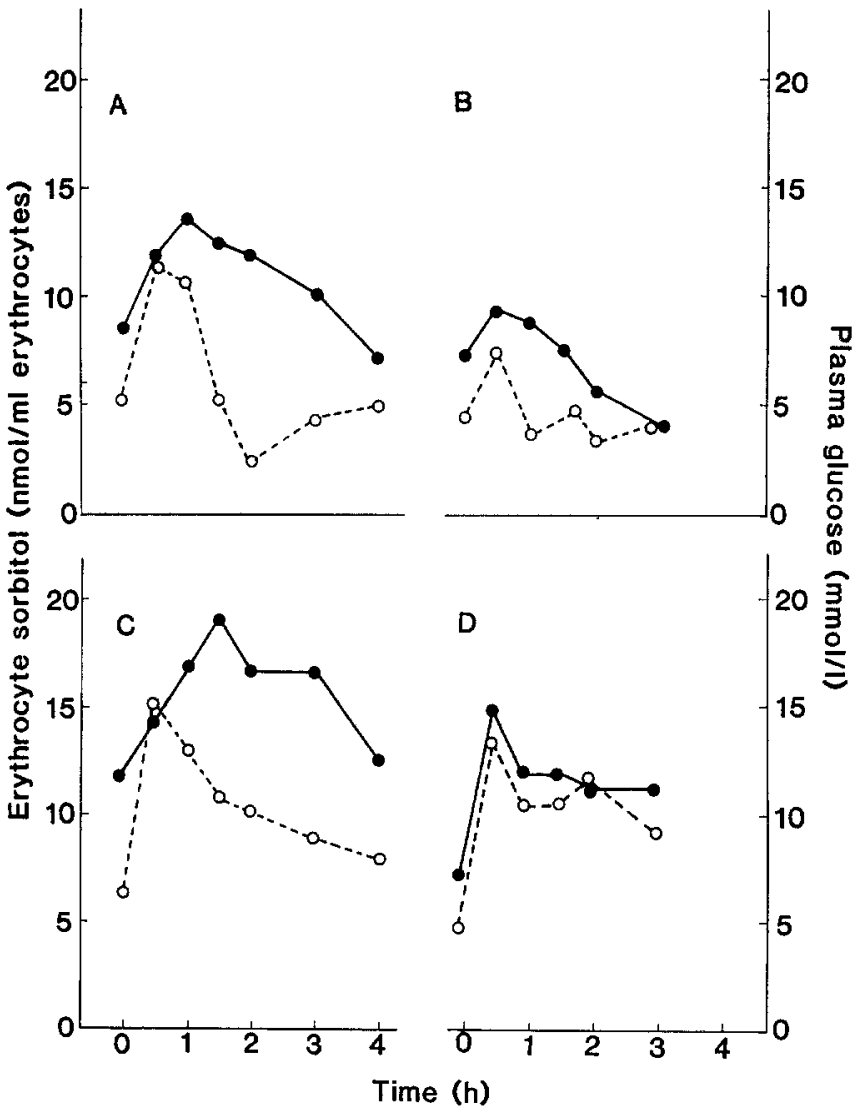

Fig. 3. Time course of plasma glucose and erythrocyte sorbitol levels in $75 \mathrm{~g}$ oral glucose tolerance test. Non-diabetic subjects with gastrectomy (A and B) and diabetic patients with gastrectomy (C and D). Plasma glucose $\left(\mathrm{O}^{-\cdots} \mathrm{O}\right)$, erythrocyte sorbitol $(\longrightarrow)$

Table 1. Sorbitol/glucose ratio in subjects with gastrectomy who were placed on a $75 \mathrm{~g}$ oral glucose tolerance test

Sorbitol/glucose ratio (min)

\begin{tabular}{llllllll} 
Time & 0 & 30 & 60 & 90 & 120 & 180 & 240 \\
\hline Case 1 & 1.07 & 0.92 & 1.28 & 1.70 & 1.62 & 1.86 & 1.56 \\
Case 2 & 1.50 & 1.11 & 1.13 & 1.13 & 0.98 & 1.24 & - \\
Case 3 & 1.65 & 1.03 & 1.27 & 2.43 & 5.10 & 2.33 & 1.43 \\
Case 4 & 1.58 & 1.27 & 2.38 & 1.65 & 1.74 & 1.00 & -
\end{tabular}

Cases 1 and 2 are diabetic patients with gastrectomy. Cases 3 and 4 are non-diabetic subjects with gastrectomy. Sorbitol/glucose ratio expressed sorbitol levels ( $\mathrm{nmol} / \mathrm{ml}$ erythrocytes) as a function of the coincident plasma glucose concentration ( $\mathrm{mmol} / \mathrm{l}$ )

In Figure 2, the rate of oxidation of the increased sorbitol is indicated. In erythrocytes from 5 healthy and 4 diabetic subjects, pre-incubation levels of intracellular sorbitol were $11.1 \pm 2.2 \mathrm{nmol} / \mathrm{ml}, 6.5 \pm$ $1.4 \mathrm{nmol} / \mathrm{ml}$ and they reached $25.5 \pm 4.3 \mathrm{nmol} / \mathrm{ml}$, $21.8 \pm 5.3 \mathrm{nmol} / \mathrm{ml}$ after $1 \mathrm{~h}$ incubation with $30 \mathrm{mmol} / 1$ glucose and returned to $12.0 \pm 0.5 \mathrm{nmol} / \mathrm{ml}, 7.1 \pm$ $1.2 \mathrm{nmol} / \mathrm{ml}$ within $2 \mathrm{~h}$ during incubation with $5 \mathrm{mmol} / 1$ glucose respectively. Fructose concentration $(410.2 \pm 169.0 \mu \mathrm{mol} / \mathrm{l})$ in the medium at the end of $1 \mathrm{~h}$ incubation of erythrocytes from healthy subjects with $50 \mathrm{mmol} / 1$ glucose resulted in an approximate 8-fold increase compared to those with $5 \mathrm{mmol} / 1$ glucose $(51.2 \pm 15.8 \mu \mathrm{mol} / \mathrm{l})$. Sorbitol was not detectable in the medium. This is in agreement with a previous observation that sorbitol cannot cross the erythrocyte membrane [9]. Because the erythrocyte membrane is easily permeable to fructose $[9,16,19]$, increased fructose in the medium substantially reflects increased production of fructose in erythrocytes.

Gastrectomised non-diabetic and diabetic subjects underwent a $75 \mathrm{~g}$ oral glucose tolerance test to investigate the relationships between plasma glucose and erythrocyte sorbitol levels (Fig.3). Characteristically, two non-diabetic subjects showed a rapid increase of plasma glucose levels, achieving a peak of 11.6 and $7.4 \mathrm{mmol} / 1$, followed by an abrupt descent to hypoglycaemic levels (Fig. 3A and B). They, therefore, appear to be analogous to our in vitro incubation studies. In this situation, the response of erythrocyte sorbitol to the changes of plasma glucose levels was very similar to those seen in in vitro studies (Fig.2). Two diabetic patients with gastrectomy also showed a rapid increase of plasma glucose levels, followed by a rapid increase in sorbitol levels. As plasma glucose concentration gradually decreased, erythrocyte sorbitol levels gradually returned to the fasting levels (Fig. 3C and D). The data presented indicate that the rapid changes of sorbitol occur not only in vitro but also in vivo.

Sorbitol/glucose ratios also fluctuated widely in response to changes of plasma glucose concentration, the values in diabetic patients being similar to those in non-diabetic subjects (Table 1).

The glycolytic intermediates and nucleotides except adenosine $5^{\prime}$-triphosphate (ATP) and lactate were found to have no effect on sorbitol dehydrogenase activity. Three mmol/1 ATP and $5 \mathrm{mmol} / 1$ lactate caused approximately $40 \%$ inhibition of sorbitol dehydrogenase activity. Even $1 \mathrm{mmol} / 1$ fructose above physiological concentration had no inhibitory effect on sorbitol dehydrogenase activity.

\section{Discussion}

Clinical application of erythrocyte sorbitol measurements as an index of medium or long term glycaemic control has been proposed [1-3], while additional clinical data has failed to demonstrate consistent relationships between erythrocyte sorbitol levels and $\mathrm{HbA}_{1}$ [6]. As shown in Figures 1 and 2, our incubation studies indicated that erythrocyte sorbitol increased rapidly in response to the ambient glucose concentration, while accumulated sorbitol decreased easily according to the rapid reduction of glucose concentration. Similar results were also obtained during $75 \mathrm{~g}$ oral glucose tolerance tests. The results are consistent with the previous observation that erythrocyte sorbitol levels correlated well with coincident 
plasma glucose levels [5]. These findings strongly indicate that the measurement of erythrocyte sorbitol is not useful as an index of medium or long term glycaemic control.

Another trend of using erythrocyte sorbitol measurements is the attempt to obtain representative sorbitol levels in less accessible tissues. In streptozotocin-induced diabetic rats, significant correlations of sorbitol levels between erythrocytes and the sciatic nerve or the lens were reported, proposing that erythrocyte sorbitol might be useful to monitor sorbitol levels in these tissues $[3,17]$, thus rendering erythrocyte sorbitol/glucose ratio helpful in assessment of the polyol pathway activities [18]. However, erythrocytes have much lower sorbitol concentrations than lens or peripheral nerve in diabetic subjects. Sorbitol levels in lens and peripheral nerve do not fluctuate as rapidly as in erythrocytes [6]. In addition, the results of the oral glucose tolerance test (Fig.3) indicate that sorbitol/glucose ratios change widely in response to changes in plasma glucose concentration. Therefore, it is concluded that erythrocyte sorbitol may not represent polyol pathway activity in other tissues.

Intracellular sorbitol levels reflect an equilibrium between production and turnover [9]; thus, the enhanced accumulation during higher glucose concentrations appears to be a result of increased synthesis and/or decreased breakdown.

Human erythrocytes are highly permeable to glucose, and the time needed to attain equilibrium between outer and inner membrane layers is 1 or $2 \mathrm{~min}$ $[19,20]$. Therefore, entry of glucose into erythrocytes is not a rate-limiting step of intracellular glucose utilisation. Since the reduction of glucose by aldose reductase follows classical Michaelis-Menten kinetics and the reported $\mathrm{Km}$ of aldose reductase for glucose is $9 \mathrm{mmol} / 1$ [8], the calculated velocity of sorbitol synthesis at $50 \mathrm{mmol} / 1$ glucose should increase 2.4 -fold as compared to $5 \mathrm{mmol} / \mathrm{l}$. As shown in Figure 1, however, sorbitol synthesis increased several-fold in our present study. Therefore, the accelerated accumulation of sorbitol at the higher glucose concentration seems not to be merely due to increased availability of glucose to aldose reductase.

Aldose reductase is activated by glucose-6-phosphate and inhibited by glycerate-2,3-bisphosphate [8]. The former is consistently elevated and the latter decreased in hyperglycaemic states, both in vivo and in vitro [7, 21-23]. Therefore, sorbitol synthesis may be more activated at the higher glucose concentration.

Another possibility is a decreased rate of sorbitol breakdown. High $\mathrm{NADH} / \mathrm{NAD}^{+}$ratios inhibit the sorbitol dehydrogenase reaction. However, increased ratios of $\mathrm{NADH} / \mathrm{NAD}^{+}$as found in hyperglycaemic states [12] are not sufficient to reverse the reaction [24]. Among glycolytic intermediates, nucleotides and fructose, only ATP and lactate were found to have inhibitory effects on sorbitol dehydrogenase activity, but none of them were increased in diabetic patients [21] and after incubation of erythrocytes with high concentrations of glucose [12]. On the contrary, an 8-fold increase of fructose concentration after $1 \mathrm{~h}$ incubation with $50 \mathrm{mmol} / 1$ observed in our experiments may indicate the acceleration of sorbitol breakdown rather than its inhibition. This agrees with a previous report that exposure of the lens to elevated glucose levels resulted in marked increases in both sorbitol production and turnover [25]. From these findings, it is unlikely that sorbitol dehydrogenase contributes to sorbitol accumulation during hyperglycaemia.

Our studies further support recent clinical studies that erythrocyte sorbitol level is well correlated with the ambient plasma glucose concentration [5] and provide the basis to conclude that measurement of erythrocyte sorbitol means nothing more than the easy measurement of plasma glucose.

Acknowledgements. We thank to Dr. M. Matsuda for helpful discussion and Dr. Y. Yoshizaki for technical assistance.

\section{References}

1. Malone JI, Knox G, Benford S, Tedesco TA (1980) Red cell sorbitol. An indicator of diabetic control. Diabetes 29: 861-864

2. Lapolla A, Poli T, Valerio A, Fedele D (1985) Is red cell sorbitol content a good marker of glycemic control in diabetic patients? Diabetes Res 2: 283-286

3. Hotta N, Kakuta T, Fukusawa H, Kimura M, Koh N, Iida M, Terashima H, Morimura T, Sakamoto N (1985) Effects of a fructoserich diet and the aldose reductase inhibitor, ONO-2235, on the development of diabetic neuropathy in streptozotocin-treated rats. Diabetologia 28: 176-180

4. Hubinont C, Sener A, Malaisse WJ (1981) Sorbitol content of plasma and erythrocytes during induced short-term hyperglycemia. Clin Biochem 14: 19-20

5. Akgun S, Ertel NH, Kemp FW (1985) Red cell sorbitol and diabetic control. Horm Metab Res 17: 355-357

6. Somers G, Depoorter I, Sener A, Malaisse WJ (1982) Sorbitol concentration in the plasma and erythrocytes of diabetic subjects. Diabetes Care 5:319-321

7. Fujii S, Beutler E (1985) High glucose concentration partially release hexokinase from inhibition by glucose 6-phosphate. Proc Natl Acad Sci USA 82: 1552-1554

8. Srivastava SK, Hair GA, Das B (1985) Activated and unactivated forms of human erythrocyte aldose reductase. Proc Natl Acad Sci USA 82: 7222-7226

9. Morrison AD, Clements Jr RS, Travis SB, Oski F, Winegrad AI (1970) Glucose utilization by the polyol pathway in human erythrocytes. Biochem Biophys Res Commun 40: 199-205

10. Beutler E, West C, Blume KG (1976) The removal of leukocytes and platelets from whole blood. J Lab Clin Med 88: 328-333

11. Beutler HO (1984) D-Sorbitol, In Methods of enzymatic analysis vol. 4 Bergmeyer HU Ed. Verlag Chemie, Weinheim, pp 356-362

12. Travis SF, Morrison AD, Clements Jr RS, Winegrad AI, Oski FA (1971) Metabolic alterations in the human erythrocyte produced by increases in glucose concentration. The role of the polyol pathway. J Clin Invest 50: 2104-2112

13. Kunst A, Draegan B, Ziegenhon J (1984) UV-method with hexokinase and glucose-6-phosphate dehydrogenase. In Method of enzymatic analysis vol. 4 Bergmeyer HU Ed. Verlag Chemie, Weinheim, pp 163-172 
14. Beutler HO (1984) D-Fructose. In Method of enzymatic analysis vol. 4 Bergmeyer HU Ed. Verlag Chemie, Weinheim, pp321-327

15. Barretto OCO, Beutler $E$ (1975) The sorbitol-oxidizing enzyme of red blood cells. J Lab Clin Med 85: 645-649

16. Torrance JD (1973) The role of fructose in restriction of organic phosphate compounds in outdated bank blood. J Lab Clin Med 82: 489-499

17. Malone JI, Leavengood $\mathrm{H}$, Peterson MJ, O'brien MM, Page MG, Aldinger CE (1984) Red cell sorbitol as an indicator of polyol pathway activity. Inhibition by sorbinil in insulin-dependent diabetic subjects. Diabetes 33: 45-49

18. Malone JI, Knox G, Harvey C (1984) Sorbitol accumulation is altered in Type 1 (insulin-dependent) diabetes mellitus. Diabetologia 27: $509-513$

19. Widdas WF (1954) Facilitated transfer of hexoses across the human erythrocyte membrane. J Physiol 125: 163-180

20. Widdas WF (1954) Hexose permeability of foetal erythrocytes. J Physiol 127: 318-327

21. Tegos C, Beutler E (1980) Red cell glycolytic intermediates in diabetic patients. J Lab Clin Med 96: 85-89

22. Alberts KGMM, Darly JH, Emerson PM, Hockaday TDR (1972) 2,3-Diphosphoglycerate and tissue oxygenation in uncontrolled diabetes mellitus. Lancet II: 391-395
23. Ditzel J (1972) Impaired oxygen release caused by alterations of the metabolism in the erythrocytes in diabetes Lancet I: 321-323

24. Jedziniak JA, Chylack Jr LT, Cheng HM, Gillis MK, Kalustian AA, Tung WH (1981) The sorbitol pathway in the human lens: aldose reductase and polyol dehydrogenase. Invest Ophthalmol Vis Sci 20: $314-326$

25. Gonzalez RG, Barnett P, Aguayo J, Cheng HM, Chylack Jr LT (1984) Direct measurement of polyol pathway activity in the ocular lens. Diabetes 33: 196-199

Received: 17 February 1988

and in revised form: 2 August 1988

Dr. Y. Nagasaka

The Third Department of Internal Medicine

Yamaguchi University

School of Medicine

Ube, Yamaguchi 755

Japan 